\title{
La enseñanza del Derecho como política pública
}

GORKI GONZALES MANTILLA*

A la memoria de Armando Zolezzi Möller

SUMARIO. PRESENTACIÓN.- I. EL CARÁCTER POLÍTICO DE LA ENSEÑANZA DEL DERECHO.- II. LAS FACULTADES DE DERECHO Y LAS POLÍTICAS PÚBLICAS: EL PAPEL DE LOS ABOGADOS.- III. EL PROBLEMA DEL PERFIL, EL MERCADO Y LOS VALORES DE LA DEMOCRACIA CONSTITUCIONAL.

\section{PRESENTACIÓN}

En este trabajo me ocuparé de examinar la relación entre el carácter de la formación legal y su incidencia en el sentido de la democracia constitucional. El propósito es argumentar sobre la idea de la enseñanza del Derecho como una actividad de raigambre política. Se postula que esta noción debe ser parte de la responsabilidad institucional de las facultades de Derecho, más allá del objetivo formal que se predica con la idea de producir profesionales.

Por lo tanto, se sostiene que el perfil como centro de gravedad de la educación legal no es solo un problema técnico que se agote en el plan de estudios. La concepción del Derecho - y su relación con la democracia- presente en la configuración del perfil profesional y en la práctica docente, está fuertemente vinculada a los objetivos que se espera lograr con este tipo de formación. Estos objetivos, no está demás decirlo, implican por lo general preferencias y valoraciones de orden ideológico que trascienden el plano de los enunciados formales que se describen en el propio perfil.

El carácter político de la educación legal y sus consecuencias sobre la democracia constitucional permiten reflexionar sobre el papel del mercado y las condiciones que deben valorarse en este contexto cuando se responde a la pregunta sobre el problema de las facultades de Derecho en el país. Reconsiderar la idea que equipara la enseñanza legal a un hecho económico es un punto prevalente en esta línea de análisis. 


\section{EL CARÁCTER POLÍTICO DE LA ENSEÑANZA}

DEL DERECHO

La política y el poder están en la base de la formación legal, y los derechos son parte de este proceso como factores de coordinación y legitimidad. Este punto de vista tiene dos niveles de análisis que se entienden en función de la relación entre la política como acto cultural y el Derecho como política.

La primera cuestión implica reconocer que la política representa un acto cultural — en términos de Arendt ${ }^{1}$ — que hace posible la realización de la libertad ${ }^{2}$ bajo ciertas condiciones. Por encima de los prejuicios y de las desvaloraciones que los políticos puedan haber causado, la política, en sus rasgos esenciales, es el instrumento que permite modelar los escenarios institucionales básicos ${ }^{3}$ de la vida en comunidad.

Esa visión de la política parte de reconocer que la cultura es un presupuesto de la convivencia, pues en ella adquiere vida la diversidad en toda su magnitud; pero, sobre todo, porque la cultura es el espacio que permite intercambiar opiniones, argumentar y negociar, es decir, ejercer el poder. La cultura se convierte en la atmósfera que permite la producción, el acceso o la lucha por el poder ${ }^{4}$. Este es el sentido relevante de lo cultural inherente al poder y a la forma de articularlo a través de la política, más relevante aún en la caracterización plural de las democracias constitucionales 5 .

Conforme a lo dicho, el segundo nivel de análisis reconoce en la educación legal una forma específica del ejercicio del poder vinculado a una actividad que no puede ocultar su carácter político. La formación que se brinda en las facultades de Derecho responde a la idea de proveer herramientas teóricas, destrezas y competencias, identificadas por una

1 Véase ARENDT, Hanna. ¿Qué es la política? Barcelona: Ediciones Paidós, 1997, p. 45. «La política trata del estar juntos y los unos con los otros de los diversos. Los hombres se organizan políticamente según determinadas comunidades esenciales en un caos absoluto, o a partir de un caos absoluto de las diferencias. En la medida en que se construyen cuerpos políticos sobre la familia y se los entiende a imagen de ésta, se considera que los parentescos pueden, por un lado, unir a los más diversos y, por otro, permitir que figuras similares a individuos se distingan las unas de las otras».

2 lbíd., p. 73.

3 No parece extraña la perspectiva así enfocada, si se observa el sentido cultural que adquiere la política en el itinerario de lo cotidiano que termina por constituir la base de las instituciones públicas. Así, se ha dicho: «Las instituciones reducen la incertidumbre por el hecho de que proporcionan una estructura a la vida diaria. Constituyen una guía para la interacción humana, de modo que cuando deseamos saludar a los amigos, manejar un automóvil, comprar naranjas, pedir dinero prestado, establecer un negocio, enterrar a nuestros muertos, o cualquier otra cosa sabemos (o podemos averiguar con facilidad) cómo realizar esas actividades. De inmediato observaremos que las instituciones difieren cuando tratamos de realizar esas mismas operaciones en un país diferente, por ejemplo, Bangladesh". En Instituciones, cambio institucional y desempeño económico. México D.F.: Fondo de Cultura Económica, 1990, p.14.

4 Véase FAmiglietti, Gianluca. Diritti culturali e diritto della cultura. La voce cultura dal campo delle tutele a quello della tutela. Torino: Giappichelli Editore, 2010, p. 190.

5 Como ha sido dicho por el profesor Häberle, en las democracias constitucionales «[...] la Constitución no es sólo un texto jurídico o un 'mecanismo normativo', sino también expresión de un estadio de desarrollo cultural, medio para la representación cultural del pueblo ante sí mismo, espejo de su patrimonio y fundamento de sus esperanzas». Véase El Estado constitucional. Lima: Universidad Nacional Autónoma de México y Fondo Editorial de la Pontificia Universidad Católica del Perú, 2003, p. 5. 
perspectiva ideológica comprehensiva que se vale de un tipo particular de razonamiento práctico y de un discurso útil para transmitirlo ${ }^{6}$. Este conjunto de elementos sirve, entre otras cosas, para justificar el quehacer de los abogados en la constitución de intereses y posiciones de poder, asumidos como legítimos en la sociedad?

El carácter político de la formación legal, así descrito, hace posible que se establezcan las bases culturales del ordenamiento legal; permite gestar el contenido valorativo del Derecho, por ejemplo, el lugar de la justicia; y explica la definición de las funciones atribuidas al sentido del Derecho. En perspectiva, la enseñanza del Derecho, por encima de su incidencia en la formación de abogados, cumple una función decisiva en el diseño y en el sentido de la democracia como un todo.

\section{I.1 Las facultades de Derecho como fuente autoritativa de la cultura legal}

A través de la enseñanza del Derecho se vertebran y actualizan las bases de la cultura legal. En efecto, en las facultades se transmiten los conocimientos, las instituciones y las convicciones ideológicas relativas a la actividad de los abogados, como herramientas para justificar su práctica expositiva e interpretativa ${ }^{8}$. Se entiende, por ello y por su impacto en las instituciones y en el orden que ellas reflejan, el valor instrumental de la enseñanza del Derecho, Las facultades de Derecho cumplen, así, una función relevante en la configuración del contenido de la cultura legal, es decir, en la definición del sentido atribuido a los derechos y a los valores que ellos implican en su actuación.

Una formación sistemática y homogénea, en sus líneas generales, que permite la adquisición de un conocimiento especializado, es la base de la cultura legal, del uso de dicho «saber» a cambio de contraprestaciones, del monopolio sobre el ejercicio de las atribuciones propias de la profesión legal y de la adquisición de un status profesional ${ }^{9}$. Las facultades de Derecho son el soporte estructurado de la cultura legal. Ellas cumplen una función autoritativa respecto de la pertenencia a la comunidad y autorizan, también, en forma directa o por omisión, las claves ideológicas que atribuyen sentido a la cultura legal.

6 Gonzales Mantilla, Gorki. La enseñanza del Derecho o los molinos de viento. Cambios resistencias y continuidades. Lima: Pontificia Universidad Católica del Perú y Palestra Editores, 2008, p. 16. De otra parte, el tipo de razonamiento y el discurso como instrumento abierto de comunicación, pero al mismo tiempo delimitado por las condiciones de lo constitucionalmente plausible, componen los rasgos básicos de la idea del Derecho en su actuación por los abogados. Véase ALEXY, Robert. Teoría de la argumentación jurídica. Lima: Palestra Editores, 2007, 293 y siguientes.

7 Gonzales Mantilla, Gorki. La enseñanza del Derecho o los molinos de viento. Ob. cit., p. 16.

8 Al respecto, véase TARELLO, Giovanni. Cultura jurídica y política del derecho. México: Fondo de Cultura Económica, 1995, pp. 181-182. También véase GoNZALES MANTILLA, Gorki. Los jueces. Cultura jurídica y carrera judicial. Lima: Pontificia Universidad Católica del Perú y Palestra Editores, 2009, p. 122.

9 Véase sobre estas condiciones, SILVA GaRcía, Germán. El mundo real de los abogados. Tomo I. La profesión jurídica. Bogotá: Universidad Externado de Colombia e Instituto Latinoamericano de Servicios Sociales Alternativos, 2001, pp. 30-31. 
Conforme a lo expuesto, los rasgos de la educación jurídica responden a las coordenadas de la cultura legal imperante, pero la fuerza de esta influencia está asociada a las variables que resultan de los acuerdos institucionales de cada facultad. Es bueno precisar que tales arreglos tampoco se expresan únicamente en el plan de estudios. En el fondo, su real importancia se revela en las prácticas docentes que lo hacen efectivo. En este escenario es donde la cultura jurídica emerge para hacer posible la continuidad de la concepción y la práctica del Derecho; así ,modelan el plan de estudios real y, desde esa óptica, el perfil del abogado.

\section{I.2. Las facultades de Derecho y sus funciones sobre el sentido del Derecho.}

La enseñanza legal provee los supuestos que determinan la idea del Derecho en su contenido, respecto de cómo se produce y cómo se aplica. Esta característica se reflejará luego en el sentido de las propias instituciones públicas como resultado de la práctica de los abogados.

En efecto, la práctica legal y su relación con los valores constitucionales parte de la caracterización en la teoría jurídica que se produce en las facultades de Derecho y que, con mayor o menor conciencia y elaboración, se mantiene en la actividad docente ${ }^{10}$. En líneas generales, la teoría del Derecho busca ser comprehensiva y útil para nombrar y establecer los límites respecto de las cosas nombradas en términos del Derecho. Tiene la aspiración de determinar el campo de «lo legal» ${ }^{11}$. Las piezas de esta teoría proceden de diversas fuentes, dependiendo del enfoque y de los intereses o de los actores que se busquen privilegiar.

La intensidad de los valores constitucionales y la justicia como referentes en esta teoría puede depender de diversos factores. Una teoría legal afiliada a la creencia en el Derecho como un orden cerrado, que produce certeza y que es capaz de brindar respuestas correctas, distantes de los referentes sociales, políticos, filosóficos o morales, es una teoría ineficaz para enfrentar la dinámica de la realidad social ${ }^{12}$. Pero, sobre todo, es una comprensión de «lo legal» donde los valores constitucionales y la justicia no ocupan lugar alguno o se mantienen como aspectos ajenos al Derecho ${ }^{13}$.

Con ciertos matices, estos son los rasgos de la teoría jurídica que ha predominado en el Perú. Su versión más extrema, el formalismo, como dogmática autorreferencial, se articula a la creencia en el Derecho de los libros frente al Derecho en acción, a la creencia en el silogismo jurídico,

10 GonZales MANTILLA, Gorki. Los jueces... Ob. cit., p. 496.

11 Bourdieu, Pierre. «Elementos para una sociología del campo jurídico». En La fuerza del Derecho. Bogotá: Ediciones Uniandes, Instituto Pensar y Siglo del Hombre Editores, 2000, p. 159.

12 Al respecto, véase GonZALES MANTILLA, Gorki. Los jueces... Ob. cit., pp. 126-127.

13 Esta idea guarda relación con el carácter del trabajo jurídico en el formalismo. La actividad se presenta inscrita en una lógica quizás coherente con la conservación acrítica del orden establecido, como rasgo característico de su funcionamiento. Véase BouRdieU, Pierre. «Elementos para una sociología del campo jurídico». Ob. cit., p. 209. 
en la predictibilidad como ideal del Derecho, en la lógica interna del Derecho, o la abstracción y generalidad como cualidades esenciales de las normas ${ }^{14}$. A esta visión corresponde un escaso interés por desarrollar una práctica argumentativa propia, relativa a la realidad, a los problemas sociales y a la eficacia compleja y crítica de las decisiones judiciales ${ }^{15}$. Este tipo de análisis carece de relevancia en los términos de la teoría misma y con ello, el campo del Derecho se mantiene adscrito a los intereses ocultos detrás de las normas escritas o de las decisiones judiciales sin motivación.

Es importante resaltar la función de interpretar el Derecho en el enfoque formalista. Debido a su vinculación con la voluntad del legislador, presente en el texto o en los prolegómenos que dieron lugar a la definición legislativa ${ }^{16}$, la interpretación se convierte en una herramienta útil para tornar invisible la realidad y alentar la ausencia de crítica al Derecho. Esta última se verifica en la renuencia o dificultad para aceptar consideraciones de orden moral y político que puedan articularse al razonamiento jurídico conforme a las exigencias de la práctica de los casos concretos.

Un resultado práctico de lo anterior es que las causas materiales de la desigualdad no son objeto de cuestionamiento; peor aún, se refuerzan las condiciones que legitiman la exclusión debido a que este tipo de razonamiento jurídico omite la presencia de la realidad. Desde esta perspectiva, el formalismo impreso en la formación legal acentúa la clandestinidad respecto de los actos de los operadores y optimiza las condiciones que hacen posible la corrupción.

La teoría del Derecho, en cambio, puede responder a la preocupación por la estructura social y moral presente en los conflictos. En ese sentido, puede afianzar sus preceptos en los principios constitucionales y en la impronta moral que la Constitución supone, cuando esta se entiende como un estado de la cultura y, por ello, como medio para la realización de los derechos y libertades fundamentales ${ }^{17}$.

La teoría del Derecho, en estos términos, admite la presencia de la política y la crítica moral como factores que deben ser dilucidados en su órbita ${ }^{18}$. Y desde esa misma perspectiva se asume que los derechos fundamentales, pese a su inserción en el texto constitucional, que permite

$14 \mathrm{Al}$ respecto, véase GaRcía FIgUeROA, Alfonso. Criaturas de la moralidad. Una aproximación neoconstitucionalista al Derecho a través de los derechos. Madrid: Editorial Trotta, 2009, p. 71.

15 No es extraño que la fuerza de la teoría, así concebida, delimite el sentido que adquiere el análisis de la jurisprudencia en términos puramente formales.

16 Como bien afirma el profesor de la Universidad de Texas, Lawrence G. Sager, las teorías constitucionales que apelan a esa forma de entender la interpretación sitúan al juez en el papel de simple agencia del legislador histórico, vinculado a él a través de los textos jurídicos. Véase SAGER, Lawrence G. Juez y democracia. Una teoría de la práctica constitucional norteamericana. Madrid y Barcelona: Marcial Pons Ediciones Jurídicas y Sociales, 2007, p. 55.

17 Véase HÄBERLE, Peter. El Estado constitucional. Ob. cit., p. 5.

18 FERRAJOLI, Luigi. «Lo Stato di diritto fra pasato e futuro». En Lo Stato di diritto. Storia, teoria, critica. Milán: Feltrinelli Editore, 2003, pp. 354-355. 
considerarlos como objeto de garantía respecto de las normas subordinadas —orientadas por valores compartidos y esenciales para la sociedad- desde un enfoque más integral, son también instituciones: es decir, un complejo de reales expectativas de comportamiento actualizadas en el contexto social. Son instituciones que se afirman y desarrollan en la historia, y que hacen frente a precisas exigencias sociales ${ }^{19}$.

La enseñanza de este tipo de teoría apunta a considerar que el centro de gravedad de la actividad del Estado y el Derecho no se constriñe a asegurar las garantías formales de la libertad, sino a establecer una situación jurídica justa en sentido material ${ }^{20}$. Con tal propósito, esta teoría se construirá en su relación con la práctica de los tribunales ${ }^{21}$. Esta forma de entender la teoría legal la libera de servir únicamente a la simple exposición del Derecho legislado. Será, más bien, un instrumento que integra el razonamiento para reconstruir la propia práctica jurídica ${ }^{22}$.

La interpretación del Derecho, además de considerar la influencia permanente de la Constitución desde este enfoque, admite la necesidad de la justificación crítica como resultado de reconocer que el razonamiento jurídico es una forma particular del razonamiento práctico general. En consecuencia, la norma jurídica adquiere un sentido diferente, pues la interpretación de esta resulta de su confrontación con los hechos del caso. No hay voluntad del legislador que deba buscarse para dar la respuesta al problema que se busca resolver. Ahora la interpretación deberá atribuir un sentido y valor como resultado de la realidad del caso y de los principios de la Constitución implicados a través de las normas ${ }^{23}$.

Sobre la base de estas coordenadas y de su influencia, se observa el impacto que la enseñanza legal genera sobre la teoría del Derecho y la perspectiva que esta propicia en las propias destrezas de la práctica profesional. El resultado, debido a la propia actividad de los abogados, tendrá consecuencias en el ámbito de las instituciones y en el sentido que los derechos adquieren en la realidad.

\section{I.3. Las escuelas de leyes y el contenido valorativo del Derecho}

Por su función autoritativa en la conformación de la cultura legal, las facultades de Derecho cumplen un rol relevante en el lugar atribuido a

19 Véase LUHMAN, Niklas. I diritti fondamentali como istituzione. Bari: Edizione Dedalo, p. 11.

20 BÖCKENFÖRDE, Ernst Wolfang. Estudios sobre el estado de Derecho y la democracia. Madrid: Editorial Trotta, 2000, p. 40.

21 Anótese, en la línea expuesta por el profesor Duncan Kennedy que «[...] un campo jurídico es muchísimo más que una mera colección de normas generales, límites, precedentes y vectores». Cuenta también la libertad y la propia restricción del intérprete. Véase KENNEDY, Duncan. Libertad y restricción en la decisión judicial: una fenomenología crítica. Bogotá: Universidad de los Andes, Pontificia Universidad Javeriana, Ediciones Uniandes, Instituto Pensar y Siglo del Hombre Editores, 1999, p. 157.

22 LÓPEZ MEDINA. Diego. El Derecho de los jueces. Bogotá: Universidad de Los Andes y Legis, 2006, pp. 285-286.

23 ZAGREBELSKY, Gustavo. I/ diritto mite. Legge, diritti, giustizia. Turín: Einaudi, 1992, p. 188. 
los valores de la Constitución como conjunto ordenador de la vida en comunidad. No hay que olvidar que es gracias a la educación legal y a la práctica de los abogados que se consagra el orden establecido ${ }^{24}$, es decir, los derechos, las posiciones de poder, las instituciones, las competencias y los procesos. La legitimidad de este orden radica en la aptitud concreta que los derechos y políticas institucionales tienen para realizar los valores previstos por la Constitución. Como parte de esos valores el lugar de la justicia es pertinente, pues ella permite resolver la tensión que existe entre el acceso a los derechos y las responsabilidades o cargas. Esta es la base constitutiva del orden establecido y sobre ella incide el ejercicio de la profesión legal.

Sobre esta línea, la enseñanza del Derecho influye en la forma en que se relacionan los valores de la Constitución y los derechos o la aptitud de estos para realizarlos ${ }^{25}$. El tipo de formación jurídica y la práctica legal (conocimientos y destrezas) pueden servir para auspiciar o bien para debilitar la posición atribuida a la justicia y a los valores constitucionales: por ejemplo, una educación legal enfocada en el aprendizaje de la ley y en las teorías como argumentos de autoridad producirá una práctica legal distante de la realidad de los $\operatorname{casos}^{26} y$, por ello, ajena a los derechos y a la justicia. Es probable que el efecto sea diferente si la formación jurídica se produce a partir de una práctica argumentativa influida por los principios constitucionales, consciente de su papel en la formación de los valores que están en la base de los derechos individuales, comprometida con el diseño de las estructuras jurídicas para proteger los derechos de las minorías y grupos desaventajados y excluidos.

Las consecuencias del desempeño de la profesión legal como efecto del papel ejercido por las facultades de Derecho tienen enormes implicancias sociales y políticas. No está demás recordar que adjudicar derechos o asignar recursos económicos a través de políticas extrañas a la idea de justicia, además de conflictos sociales episódicos, puede generar verdaderos riesgos para la gobernabilidad democrática. Por esa razón, el acceso a la justicia, como expresión del ejercicio de los derechos y valores constitucionales, es un indicador del grado de desarrollo de una democracia constitucional.

Entonces, la responsabilidad de las escuelas de leyes en la atribución del contenido valorativo del Derecho se revela con nitidez cuando se advierte que un sistema legal puede ser ordenadoy eficiente, pero también

25 Desde una perspectiva aún no superada en el ámbito de la teoría del Derecho de nuestro medio, el debate teórico se presenta como un juego en el que el positivismo mantiene una presencia definitiva, pese a las diferencias notables sobre su significado y alcance, entre quienes comparten su prédica. Véase el interesante trabajo al respecto de GARcía FIGUEROA, Alfonso. Criaturas de la moralidad. Ob. cit., pp. 173 y siguientes.

26 Esta idea guarda relación con el carácter del trabajo jurídico en el formalismo. Esta actividad se presenta inscrita en una lógica quizás coherente con la conservación del orden establecido, como rasgo característico de su funcionamiento. Véase BouRDIEU, Pierre. Ob. cit., p. 209.

LA ENSEÑANZA DEL DERECHO COMO POLÍTICA PÚBLICA 
profundamente injusto ${ }^{27}$. Es en este punto donde la práctica legal, con todo el acervo cultural que trae consigo, se sitúa en la posibilidad de conectarse a la idea de garantizar los valores constitucionales para contribuir a corregir las inequidades y dar estabilidad al sistema social y contenido substancial a la democracia.

\section{I.4 Las facultades de Derecho, los derechos y la democracia: no solo se forman abogados}

La concepción del Derecho, su interpretación y las funciones de la teoría legal son parte fundamental del problema que define la democracia constitucional en el mundo contemporáneo, cuyo escenario está marcado por la diversidad cultural y social.

Así las cosas, la democracia puede ser definida por su capacidad para controlar el ejercicio del poder político, de modo que se conduzca dentro de los parámetros de legitimidad formal; pero, sobre todo, debe servir para crear los medios que permitan garantizar los derechos individua$\mathrm{les}^{28}$, es decir, los derechos de las minorías como base de la diversidad y fundamento del poder. Esta idea de la democracia permite afirmar que quien logre convertir en vinculante su interpretación de los derechos fundamentales «habrá convertido en parte de la Constitución su propia concepción sobre los asuntos sociales y políticos de la máxima importancia y los habrá descartado de la agenda política por encima o al margen de las mayorías políticas ${ }^{29}$.

Las facultades de Derecho se conectan con la idea de la democracia debido a que la función valorativa y el contenido atribuido a los derechos se construyen desde la formación legal. Esta particularidad no puede dejar de ser considerada en la idea de entender el tipo de responsabilidad atribuible a estas instituciones, así como para definir sus implicancias sobre la actividad docente.

La relación que las facultades de Derecho guardan con la democracia se percibe como una característica propia del escenario cultural de los regímenes constitucionales. En estos, el reconocimiento crítico de la realidad como fundamento del Derecho permite identificar en las escuelas de leyes, el papel de agentes directamente involucrados en gestar las bases culturales de quienes operan el sistema institucional de modo privilegiado $^{30}$ : los abogados. La presencia de estos en los centros y espacios de toma de decisiones los convierte en actores fundamentales del modo

27 RaWLS, John. La teoría de la justicia. México: Fondo de Cultura Económica, 1985, p. 19.

$28 \mathrm{Al}$ respecto, véase DwORKIN, Ronald. Los derechos en serio. Barcelona: Editorial Ariel, 1989, pp. 304-303.

29 Véase FERRAJOLI, Luigi. Los fundamentos de los derechos fundamentales. Madrid: Editorial Trotta, 2001, p. 35.

30 Por lo demás, esta tesis se vincula a la apertura propia del Estado constitucional hacia el pluralismo de la sociedad y a los sujetos que en ella participan como intérpretes de la Constitución: individuos, instituciones, etcétera. En, HÄBERLE, Peter. El Estado constitucional. Ob. cit., pp. 150-151. 
de ser institucional ${ }^{31}$. En otras palabras, la actuación de los abogados está comprometida con el sentido de «la democracia como un todo».

\section{LAS FACULTADES DE DERECHOYLAS POLÍTICAS PÚBLICAS: EL PAPEL DE LOS ABOGADOS}

¿Cuáles son las consecuencias prácticas que derivan de asumir el carácter político de la enseñanza del Derecho y el sentido que adquiere la práctica legal? A partir de ello, ies posible que la actividad de los abogados en las democracias constitucionales pueda ser considerada como una función distinta de la que otros profesionales realizan?

\section{II.1 Las facultades de Derecho y la idea de política pública} El carácter político de la enseñanza del Derecho y su relación con la democracia constitucional se confirma cuando se reconoce en la educación legal una orientación, con matices, equiparable a la que se produce en el caso de las políticas públicas. Recuérdese que aquellas se describen como acciones deliberadas del Estado para intervenir en el espacio público, con el propósito de hacer frente a problemas que atañen a la comunidad y a los individuos que la conforman ${ }^{32}$.

Las políticas públicas — en términos de Amartya Sen — deben valorarse por su capacidad para articular las libertades y derechos, tanto como su expansión como efecto de su aplicación. Como parece evidente, «lo público», si se piensa en este tipo de políticas, va más allá de la acción del Estado. Por lo tanto, aunque las escuelas de leyes no tengan una relación orgánica con el aparato estatal, a través de su actividad producen herramientas para dar respuesta a los conflictos que atañen a las instituciones que permiten la subsistencia de la comunidad. Esta función se deriva del carácter específico de la educación jurídica, pues, como se ha dicho, ella brinda herramientas teóricas, destrezas y competencias útiles para justificar la práctica legal y así otorgar legitimidad a determinados derechos, intereses, libertades y posiciones de poder en la sociedad.

En síntesis, las facultades de Derecho están en aptitud de propiciar políticas públicas porque, a través de la práctica legal, son capaces de definir lo que puede o no debe hacerse en los conflictos privados y lo que debe primar en el diseño y en la vida de las instituciones públicas ${ }^{33}$. En esa

31 Gonzales Mantilla, Gorki. La enseñanza del Derecho... Ob. cit., p. 96.

32 En los términos de Sen, las políticas públicas deben valorarse por su impacto en el ejercicio directo de los derechos y libertades de las personas y, por ello, en el espacio en el que desarrollan su existencia. Las políticas públicas, desde este enfoque, dejan de tener así un valor neutral enfocado en los avances que se pudieran obtener en materia de crecimiento económico. Una persona que no pueda expresarse libremente o participar en las decisiones y los debates públicos carece de algo que tiene razones para ser valorado. Véase SEN, Amartya. Desarrollo y libertad. Barcelona: Editorial Planeta, 2000, p. 99.

33 Al respecto, LASSWELL, Harold y Myres S. MCDOUGAL. «Enseñanza del Derecho y políticas públicas: entrenamiento profesional para el interés público». En La enseñanza del Derecho y el ejercicio de la abogacía. Martín F. Böhmer (compilador). Barcelona: Gedisa, 1999, pp. 75-76. Por lo demás, desde el enfoque del desarrollo humano, es posible asumir la legitimidad de la participación de las 
línea, permiten consagrar el orden establecido, es decir, el sentido y la garantía de los derechos, la posición de los valores constitucionales y la justicia en la vida ciudadana.

\section{II.2 Los abogados, la práctica legal y su relación con las políticas públicas}

Los abogados ostentan una posición particular en su relación con la actividad de los funcionarios públicos, de los empresarios, de los dirigentes gremiales o de cualquier persona que deba tomar una decisión legal de impacto público ${ }^{34}$. Más aún, no es extraño que el asesor legal de ayer se convierta en el político de hoy, y viceversa, sin pasar por alto la anomalía que esto puede significar para la transparencia de las instituciones públicas. En todo caso, la racionalidad de los abogados lleva consigo un poder estratégico que les permite influir sobre las decisiones en cuestión e incluso crearlas ${ }^{35}$.

Asimismo, la práctica legal contiene acciones y decisiones que aspiran a convertirse en verdades sobre la micro-realidad social involucrada en un caso, e incluso pretenden un alcance mayor ${ }^{36}$. Se entiende que, gracias a la práctica profesional, con el efecto de definir sus contenidos, la realidad es ajustada a sus medidas ${ }^{37}$. Entonces la interpretación proyecta la realidad, la dota de existencia, para luego confirmarla, o lo que es igual: la realidad se establece no de acuerdo con unos hechos aparentes sino en virtud de definiciones racionales atribuidas sobre ella ${ }^{38}$.

Todo este escenario - como se ha dicho en un trabajo anterior ${ }^{39}$ reclama de los abogados una actitud de lealtad con los intereses de sus clientes, pero al mismo tiempo exige un compromiso definido con el interés público que justifica la existencia del sistema lega ${ }^{40}$. De lo contrario, los abogados deberán estar dispuestos a asumir las consecuencias de su actividad, es decir, el impacto negativo que sus consejos o su asesoría produzcan en el ámbito institucional, al margen de los intereses de sus clientes. Una práctica legal no constructiva desde el punto de vista social ${ }^{41}$ traerá, en el corto o mediano plazo, un efecto corrosivo sobre las condiciones en las que el propio abogado

personas e instituciones en la vida pública para el diseño y aplicación de políticas públicas, como un factor central de esta forma de entender el desarrollo, pues así se pueden detectar sus demandas y aspiraciones. Véase el «Concepto de desarrollo humano» del PNUD. En línea: <http://www.pnud.org. pe/frmCoceptoDH.aspx>.

34 Gonzales Mantilla, Gorki. La enseñanza del Derecho... Ob. cit., p. 162.

35 En Silva García, Germán. El mundo real de los abogados y de la justicia. Tomo Il. Las prácticas jurídicas. Bogotá: Universidad del Externado de Colombia e ILSA, 2001, p. 131.

36 L. cit.

37 BouRdieu, Pierre. Ob. cit., p. 198.

38 Véase SILVA GARcía, Germán. El mundo real de los abogados y de la justicia. Ob. cit., p. 131.

39 Gonzales MANTILLA, Gorki. La enseñanza del Derecho... Ob. cit., p. 163.

40 GoRDON, W. Robert. «La práctica del Derecho empresarial como un servicio público». En La enseñanza del Derecho y el ejercicio de la abogacía. Ob. cit., p. 173.

41 lbíd., p. 202. 
debe operar ${ }^{42}$. Y el deterioro del sistema legal —que no se reduce al ordenamiento positivo- puede llegar a un punto tal que lo haga presa fácil de las dinámicas hegemónicas de los poderes fácticos. No parece irrelevante recordar que la clandestinidad de los actos, la corrupción o las prácticas elusivas del Derecho, además de llevar un costo oculto en sí mismas, y arrastrar por ello una dosis severa de ineficiencia, debilitan el marco institucional y lo hacen permeable sin atenuantes, ni crítica, a las presiones e influencias de valores ajenos a la idea de los derechos y la democracia constitucional.

Y es que la responsabilidad o el grado de influencia de la práctica legal sobre las instituciones y los derechos no deriva de la gran complejidad del caso o de la magnitud de la función ejercida por el abogado. Es la práctica legal como conjunto, es decir, el «efecto acumulado» de toda la actividad cotidiana de los abogados ${ }^{43}$, la que abre el proceso en el que se articulan, desde una perspectiva autoritativa, las relaciones sociales y los derechos ${ }^{44}$.

Las razones que fluyen de la práctica legal proveen condiciones esenciales para el debate y la deliberación pública. Además de fijar permanentemente las coordenadas del ejercicio de los derechos, se convierten en el punto de referencia para la formulación de razones críticas sobre la legitimidad de las posiciones jurídicas y políticas. Esta cualidad es crucial si se observa su impacto en el ámbito substancial de la democracia, la cual ciertamente se fortalece con el debate vigoroso y las razones públicas esclarecidas que surgen de la práctica legal.

En este panorama, el ejercicio de la profesión legal implica mucho más que la adquisición de destrezas para hacer frente a las exigencias del mercado. Valorar adecuadamente el impacto de la actividad de los abogados en el entorno institucional plantea la responsabilidad de releer los términos de la formación legal. Implica asumir, desde el significado de las políticas públicas, el sentido de los valores constitucionales que estas buscan desarrollar y que bien pueden adscribirse al carácter de la formación de los abogados.

\section{EL PROBLEMA DEL PERFIL, EL MERCADO Y LAS POLIITICAS PÚBLICAS}

Las directrices de la Constitución de una democracia constitucional son el punto ordenador de la actividad pública y deben ser el eje en torno al resultado de las acciones, de las actitudes, de las expectativas de los jueces, de los legisladores, de los funcionarios, del gobierno y de la ciudadanía en general. En NinO, Carlos Santiago. La constitución de la democracia deliberativa. Barcelona: Gedisa Editorial, 1997, p. 41. En todo este escenario, el discurso prevalente, es decir, el que debe servir para predicar las posturas y razones, proviene de la práctica de los abogados y se vertebra desde las escuelas de Derecho.

LA ENSEÑANZA DEL DERECHO COMO POLÍTICA PÚBLICA 
cual giren los componentes de la formación legal. Sin embargo, como se ha sostenido, los planes de estudios de las facultades de Derecho reflejan aún la impronta ideológica del formalismo jurídico. El perfil profesional se mueve dentro de este ámbito.

El perfil representa una categoría compleja y dinámica por su necesaria referencia social y cultural. Según se ha dicho antes ${ }^{45}$, aquel evoca el «conjunto de atributos (habilidades, actitudes y destrezas) requeridos de un sujeto para que pueda ser calificado positivamente como apto (competente) para el ejercicio de una actividad o función» ${ }^{46}$. En tanto construcción de tipo funcional, el perfil se debe al análisis de la realidad en la cual el sujeto deberá desempeñarse ${ }^{47}$, pues solo de este modo será posible incorporar «las demandas específicas del contexto, es decir, las carencias que el sujeto está llamado a satisfacer a través de su desempeño» ${ }^{48}$. Este examen debe valorar las condiciones en las cuales el sujeto habrá de operar, pero también las oportunidades para avanzar a costa de la propia realidad ${ }^{49}$. El perfil no es una entidad fija en el tiempo y, por ello, no deben fijarse consensos estáticos en torno de ella ${ }^{50}$.

\section{III.1 El perfil profesional del abogado y las estrategias del formalismo}

La fragmentación social y económica del país es un factor que define la estratificación en el ejercicio de la profesión legal e influye igualmente en la determinación del perfil del abogado. Esta realidad se refleja incluso en las condiciones fácticas en las que se desenvuelven las facultades de Derecho. Estas, en tanto se aluden a las características y oportunidades que el espacio de formación brinda, son un aspecto nada desdeñable en el análisis relativo al perfil profesional, si se piensa, por ejemplo, en la precariedad profunda de algunas universidades. Los contrastes en este extremo van de las universidades estatales a las privadas y de las privadas entre sí, dependiendo de una serie de factores visibles a partir de la realidad inaugurada con el decreto legislativo 882 de noviembre de 1996.

En consecuencia — como sugiere el profesor Germán Silva ${ }^{51}$ —, la base común en los parámetros tradicionales de la formación legal, o sea, los años de duración de los estudios y el ensamblaje general de las materias, se altera con enorme velocidad a la luz de las diferencias anotadas.

45 Gonzales MantILla, Gorki. La enseñanza del Derecho... Ob. cit., cit., p. 135.

46 FAMIGLIETTI, Gianluca. «Guía Metodológica de Lineamientos Básicos para la definición de Módulos de Capacitación de la AMAG». Con la colaboración de Gorki Gonzales. Misión Técnica Internacional para el diseño de módulos de capacitación de jueces y fiscales de la Academia de la Magistratura. Lima, marzo de 2007, p. 6.

47 L. cit.

48 L. cit.

49 L. cit.

50 lbíd. p. 7.

51 Silva García, Germán. El mundo real de los abogados y de la justicia. Las prácticas jurídicas. Ob. cit., p. 35. 
Como resultado, existen distintas formas de enfrentar la formación en términos integrales, y con ello distintos enfoques y rasgos en la configuración del perfil. Las diferencias se sitúan en los énfasis temáticos y los enfoques ocupacionales que de ello se derivan; en el grado de especialización que se logre articular desde el pregrado; en la forma como se produzcan las políticas institucionales de cada facultad; en la conformación social de la demografía estudiantil y docente que alude a la presencia o a la ausencia de perfiles socio-económicos y de la mujer; en la exigencia otorgada a la formación académica de los profesores; en la calidad de la formación que se brinde; así como en las preferencias ideológicas sobre el Derecho y su función ${ }^{52}$.

De cualquier modo, se mantienen, con mayor o menor intensidad en todos los casos, los trazos del formalismo legal, cuya teoría está en las bases constitutivas del Derecho republicano en el Perú. La capacidad de exposición del material normativo de este enfoque ha servido como herramienta de razonamiento e interpretación - textualismo interpretativo-, de dramático significado por su presencia en la base — destrezas legales- de la educación legal53.

La influencia del formalismo en la educación legal está presente de diversas formas y parece mantenerse como una constante en el pensamiento institucional de ciertas facultades de Derecho, incluso en las que se presentan como abiertas al mercado y son el resultado, en su evolución, de las formas asociativas privadas previstas en el decreto legislativo 882. De esta visión surge inclusive el sentido de la enseñanza del Derecho. Así, se ha dicho recientemente: «Es indispensable que el estudiante de Derecho estudie los textos legales, familiarizándose además con los comentarios y análisis que se hagan de ellos, iluminando el sentido confuso que eventualmente pueden tener ${ }^{54}$. Para esta perspectiva, la ley suele ser clara y, por lo tanto, la interpretación debe jugar un papel secundario, pues de lo que se trata es de respetar el texto de la ley: «[...] Hay que subrayar que, antes que interpretar las leyes, se necesita leerlas, y respetar lo que su texto señala. No siempre el texto de las leyes es confuso» ${ }^{55}$.

52 Las diferencias son visibles cuando se compraran las realidades fácticas y los planes de estudios de las facultades de Derecho de la Universidad Peruana de Ciencias Aplicadas (UPC), de la Universidad de San Marcos, de la Universidad San Juan Bautista, de la Universidad Alas Peruanas o de la Universidad de Piura.

53 GonZAles MANTILLA, Gorki. La enseñanza del Derecho... Ob. cit., cit., p. 183.

54 La cita completa es esclarecedora. Ella refleja la persistencia en algo que parece tener más contacto con la creencia que con las razones o la realidad: «Es indispensable que el estudiante de Derecho estudie los textos legales, familiarizándose además con los comentarios y análisis que se hagan de ellos, iluminando el sentido confuso que eventualmente pueden tener. Hay que subrayar que, antes que interpretar las leyes, se necesita leerlas, y respetar lo que su texto señala. No siempre el texto de las leyes es confuso". La línea de trabajo intelectual sugerida recuerda en gran medida una apología al textualismo interpretativo y proviene del decano de la Facultad de Derecho de la Universidad de Ciencias Aplicadas (UPC), José Luis Sardón, presentada en el Seminario Internacional de Enseñanza del Derecho, organizado por la Facultad de Derecho de la PUCP durante los días 9,10 y 11 de agosto de 2010 en el auditorio Armando Zolezzi Möller. Véase SARDóN, José Luis. «¿Qué abogados debemos formar?». En línea: <http://works.bepress.com/jose_luis_sardon/27/>. 
Y para reforzar determinadas opciones sobre el Derecho y el papel de los abogados se levantan tesis amparadas únicamente desde la autoridad del texto legal, y esa condición, la de «texto», se extiende en forma sorprendente incluso ante el carácter de la Constitución. Así, se afirma que el abogado «[...] debe saber también que la Constitución radica en el texto de los 206 artículos aprobados en referéndum por el pueblo peruano en $1993 »^{56}$.

Las consideraciones ideológicas sobre la función del Derecho que están detrás del énfasis en la especialización — por ejemplo, la concentración en las áreas de Derecho patrimonial para la defensa de la propiedadson justificadas igualmente con argumentos formale ${ }^{57}$ : «Hay que enfatizar, pues, que el abogado debe conocer y apegarse a los textos legales». Sobre esta línea, afirmaciones que parecen dispuestas para persuadir en la creencia en una fe permiten sostener sin mayor justificación que: «La justicia, sin embargo, no es lo que se ha dado en llamar 'justicia social'; esta es, más bien, la distorsión de la justicia» ${ }^{58}$. Y, coherente con la perspectiva formalista, la corrección de esta «distorsión» provendría directamente de la autoridad. Se afirma entonces que «Bien entendida, la justicia consiste, según la definición clásica de Ulpiano, en 'dar a cada quien lo suyo' —es decir, lo que es su propiedad [sic] ${ }^{59}$.

El formalismo, así detallado, refleja con gran intensidad el sentido que describe el perfil del abogado. Se trata de un patrón que lo encapsula en los aspectos «microjurídicos» del caso y, por su capacidad de «compartimentalizar» el carácter de las instituciones jurídicas, puede desarrollar estrategias de razonamiento que las aíslan del conjunto del Derecho y de la realidad a la que se deben los casos. En términos generales, se trata de un abogado comprometido con opciones «perfeccionistas», inevitables y enmascaradas por el discurso de la ley ${ }^{60}$. Por esa misma razón, se trata de

56 No en vano se afirma que el abogado «[...] debe saber también que la Constitución radica en el texto de los 206 artículos aprobados en referéndum por el pueblo peruano en 1993, más que en el 'bloque de constitucionalidad' imaginado después por el Tribunal Constitucional. Si lee el texto de la Constitución, en realidad, el abogado comprobará que no tiene mucho asidero el concepto de 'Estado democrático y social de Derecho', que suelen invocar las resoluciones de dicho tribunal. Diera la impresión que éste ha sido arrancado de su seno con fórceps, por vocales o asistentes de vocales que han estudiado en España, donde sí está constitucionalmente consagrado». Ibíd., p. 2.

57 En torno a lo que debe focalizar la formación del abogado, se afirma: «Hay que enfatizar, pues, que el abogado debe conocer y apegarse a los textos legales. Casi le recomendaría memorizar los Decretos Legislativos [sic] 668 y 757, que liberalizaron la economía peruana y establecieron el marco de garantías jurídicas para la inversión privada, antes de la ruptura del orden constitucional de 1992». lbíd., p. 2.

$58 \mathrm{El}$ abogado debe saber, por lo pronto, que el Derecho existe para servir a la justicia, la cual es el valor fundamental de la vida en sociedad. La justicia, sin embargo, no es lo que se ha dado en llamar «justicia social»: esta es, más bien, la distorsión de la justicia. Bien entendida, la justicia consiste, según la definición clásica de Ulpiano, en «dar a cada quien lo suyo»—es decir, lo que es su propiedad —. El Estado existe para defender la vida y la propiedad de las personas, amenazadas como están por los asesinos y ladrones que andan sueltos por ahí. Ibíd., p. 3.

59 L. cit.

60 La codificación civil y los valores morales implicados, pero al mismo tiempo «invisibilizados» por ella, es un vehículo de muchas de las opciones perfeccionistas más contrastantes con los valores constitucionales: matrimonio, posición de la mujer, el tratamiento de las personas con capacidades diferentes, denominadas paradójicamente «incapaces», son algunos de los ejemplos que proyectan los trazos perfeccionistas oficializados por el código. En efecto, «la codificación garantiza también que, salvo una revolución capaz de cuestionar los fundamentos mismos del orden jurídico, el futuro 
un abogado resistente a la crítica y al cambio, pues sus ambiciones deben cifrarse en la conservación del estado de cosas. El trabajo jurídico tiene por finalidad, desde esta óptica, mantener el «orden establecido». En este «orden», como ha quedado claro del discurso citado, los intereses que deben prevalecer corresponden al ámbito de lo privado. Lo público — incluyendo la idea de lo social — tiene una presencia accesoria y subordinada.

Al final, lo que garantiza la eficacia del perfil, así concebido, es el argumento de autoridad. Este funciona como parámetro de la interpretación legal; para ello acude a la jerarquización ex ante del ordenamiento y tiene como fundamento implícito la autoridad mayoritaria del pueblo, que ha delegado la función de legislar en su nombre ${ }^{61}$. Pero la autoridad es un argumento que también se moviliza por fuera de la ley y que discurre con facilidad en el terreno del discurso de los juristas. En vista de la división del trabajo jurídico, los juristas de esta forma de entender el Derecho precisan los límites del campo jurídico desde la teoría que al final termina por instalarse en los casos: así reemplazan a la realidad controvertida y crean fórmulas que, por definición, son inmunes a la crítica ${ }^{62}$.

En los términos expuestos, el perfil enfrenta las variables propias de las diferencias en las que se sitúan las facultades de Derecho del país. El resultado es significativo desde el punto de vista del impacto institucional. $\mathrm{Si}$ al formalismo legal se le suma la precariedad institucional, el resultado obtenido será una mezcla explosiva: la ausencia de recursos académicos, el déficit en la formación de profesores y la mala calidad en la enseñanza. Todo este conjunto de factores ofrecen un tipo de abogado cuyo perfil contrasta con el tipo de responsabilidad que debe desempeñar en el escenario de las democracias constitucionales.

\section{III.2 El perfil del abogado y el mercado: ¿el argumento de la corrección?}

A la incoherencia representada por el perfil ofrecido desde el formalismo legal y las demandas de la democracia constitucional, se le puede sumar la tesis del mercado como herramienta para corregir o ajustar la orientación de los estudios de Derecho. El problema en esta sede, sin embargo, es la idea del mercado que se abre en los hechos con enorme impacto desde el decreto legislativo 882. Es posible encarar esta cuestión desde dos puntos de vista.

es la imagen del pasado, que las transformaciones y las adaptaciones inevitables serán pensadas y habladas en el lenguaje de a conformidad con el pasado". En BOURDIEU, Pierre. Ob. cit., pp. 208-209.

61 Esta visión propia de la tradición eurocontinental ha tenido un desarrollo complejo en nuestra realidad, pero en líneas generales alude a la subordinación de la administración pública de cara a la protección del interés público preestablecido legislativamente, es decir, definido por las mayorías. Véase ZAGREBELSKY, Gustavo. El derecho dúctil. Ley, derechos, justicia. Madrid: Editorial Trotta, 1995 , p. 28 y siguientes.

62 El núcleo de esta consideración está impregnado de la tesis de la separación entre la moral y el Derecho, que permite afirmar la idea de este último desprovista de toda consideración ajena en todas sus aplicaciones. ALEXY, Robert. "Sobre las relaciones necesarias entre moral y Derecho». En Derecho y moral. Ensayos sobre un debate contemporáneo. Barcelona: Gedisa Editorial, 1998, p. 117.

LA ENSEÑANZA DEL DERECHO COMO POLÍTICA PÚBLICA 


\section{a. El mercado y la educación legal como hecho económico}

Una primera forma de entender el sentido de esta tesis proviene de considerar que el mercado produce consecuencias buenas en sí mismas, pues en un contexto de recursos escasos el espacio de agregación de preferencias que él implica es neutral por antonomasia y por ello — como dirían quienes apuestan por esta tesis - incontrastable.

La educación legal como un hecho económico es la consecuencia de esta tesis, cuya pretensión, además, es corregir toda interpretación ajena al enfoque económico. De este modo, la oferta debe responder a la demanda de educación legal de forma irremediable. Desde este razonamiento, casi resultaría irrelevante cuestionar la legitimidad de cualquiera de los extremos. Se diría que la oferta es intocable porque la demanda así lo determina. Entonces, solo quedaría esperar a que las condiciones de la demanda se modifiquen para que el cambio en la oferta se produzca. Con estas condiciones se evoca la necesidad de que se produzcan reformas institucionales profundas y complejas como las que implican, por ejemplo, la reforma del sistema de justicia, la eliminación de la corrupción o las mejoras salariales de la población ${ }^{63}$. Así las cosas, la posibilidad de transformar la demanda parecería utópica y, mientras tanto, habría que aceptar el carácter inconmovible de la oferta.

En esa ruta parecen identificarse las consecuencias del decreto legislativo 882. Gracias a ella, las libertades económicas puestas como prevalentes en las condiciones para crear entidades de educación superior están en la base del crecimiento de la oferta que aprovecha la demanda general de los estudios universitarios. En ella - aunque esto sea irrelevante para la tesis del mercado- la imagen de la profesión legal por su relación con el poder, junto a la escasa inversión que implica su funcionamiento, se asocian a la precariedad institucional que define buena parte del universo de las facultades de Derecho.

Frente a lo dicho, la iconografía del liberalismo conservador permite recordar la idea del estado de naturaleza como escenario de esta historia. Precisamente porque una de las condiciones esenciales para la existencia del mercado simplemente no existe: la información como instrumento referencial de la seguridad. Sin ella, la competencia no es tal y, por lo tanto, el mercado será pura ilusión o tierra de nadie. En este espacio, los consumidores transitarán expuestos al poder fáctico de la oferta. Sin duda alguna, este es el rasgo que mejor define el ámbito en el que se desarrolla la actividad de la mayor parte de facultades de Derecho del país.

El carácter determinista del enfoque económico para la educación legal justifica que ella se brinde sin controles razonables sobre los estándares que deberían cumplirse para ofrecer el servicio. Su punto de vista

63 Véase BULLARD, Alfredo. «Sobre abogados, mercachifles y monopolios: educación legal y libre competencia». En línea: <http://blogcristalroto.wordpress.com/2010/05/31/sobre-abogadosmercachifles-y-monopolios-educacion-legal-y-libre-competencia/>. 
descalifica la intervención del Estado en lo que considera un terreno exclusivo de la autonomía individual y de la libertad del mercado. ${ }^{64}$ Aunque no esté dicho de forma expresa, es evidente que en este enfoque el valor atribuido al mercado adquiere un significado no «derrotable». Desde esa perspectiva, la relación entre el mercado y los valores que implica una democracia constitucional puede resultar ciertamente contrastante.

Asimismo, de ser considerada un hecho económico en el marco de esta tesis, se sugiere que la enseñanza del Derecho debe ajustarse a las exigencias de la demanda. Debe tratar de ser un producto hecho a la «medida del cliente», y esa debería ser la pauta para la definición del perfil profesional y del plan de estudios. Sin embargo, el problema que este enfoque representa para la educación legal es que su sentido determinista haría posible que los valores públicos comprometidos en esta actividad se subordinen y diluyan ante los requerimientos contingentes del mercado.

Ajustar la educación legal para satisfacer al cliente en forma acrítica puede propiciar el desarrollo de un tipo de especialización fragmentada, donde la perspectiva del Derecho será igualmente parcial. La enseñanza enfocada bajo estos términos carecerá de herramientas para hacer frente a los cambios que inciden en la totalidad del Derecho y, probablemente, la idea de optimizar los derechos y mejorar la democracia desde la particular perspectiva del área de especialización no forme parte de su agenda propia.

En todo caso, es por lo menos dudosa la legitimidad de esta forma de ver la enseñanza del Derecho, orientada a satisfacer las demandas de los grupos de poder, por ejemplo, estudios de abogados o empresas. Un programa de estudios así definido seguramente levantará la necesidad de ciertos cursos y contenidos, además de la idea de las destrezas como fines en sí mismos, para enfrentar la dinámica profesional sin considerar los valores comprometidos o por encima de ellos, casi siempre para favorecer las exigencias de los grupos de interés.

\section{b. El perfil y las políticas públicas: el mercado como instrumento de la democracia}

Un punto de vista diferente proviene de asumir el carácter complejo de la actividad de las facultades de Derecho. Como se ha reiterado, a través de la enseñanza legal se construyen valores, se atribuyen funciones al

64 Sin embargo, esta idea, vista con detenimiento, es ciertamente incorrecta: el mercado está basado en la estructura de la propiedad que se establece mediante el Derecho promulgado y aplicado en forma deliberada. Este Derecho convalida los actos de posesión y de transferencia de bienes, les atribuye ciertos derechos y obligaciones y establecen sanciones penales contra quienes interfieran con ellos. Es aplicado por tribunales y otras agencias del Estado, que son sostenidos mediante ingresos derivados de los contribuyentes. Véase NINO, Carlos S. «Sobre los derechos sociales». En Derechos sociales y derechos de las minorías. México: Instituto de investigaciones Jurídicas y UNAM, p. 138.

LA ENSEÑANZA DEL DERECHO COMO POLÍTICA PÚBLICA 
Derecho y se proveen argumentos para justificar las prácticas legales. Su carácter, por lo tanto, no puede reducirse a un hecho económico y, en esa perspectiva, es posible relativizar el carácter de la tesis del mercado en la comprensión de este problema.

Es verdad que la oferta brindada por las facultades de Derecho no puede prescindir de orientar sus servicios a las demandas ciudadanas. Sin embargo, esta consideración no parece compatible con la pretensión de corrección de la tesis que equipara la educación legal con productos de consumo de carácter privado y la hace susceptible, por ello, de ser sometida al cálculo obligado por la relación entre oferta y demanda.

El carácter público de la educación legal, tanto como su articulación en los términos de una política pública, requiere de definiciones frente al mercado, pero con la finalidad de que este resulte útil desde la dimensión que le corresponde, en el escenario de la democracia constitucional, a los propósitos de la enseñanza del Derecho.

Las facultades de Derecho deben dirigir sus esfuerzos orientados hacia el cumplimiento de los objetivos sociales y políticos que definen su actividad, frente a las demandas de la comunidad, en un contexto de pluralidad y globalización ${ }^{65}$. Son estas las coordenadas que deben servir para actualizar los planes de estudios y determinar el perfil del abogado. Solo después de haberlas asumido será coherente plantear el problema de la oferta de la educación legal y el sentido que, al respecto, debería tener el mercado.

En ese propósito, la existencia de controles razonables sobre la actividad de las facultades de Derecho es un rasgo propio de los acuerdos institucionales de la democracia considerada como un todo. Este rasgo indispensable en las escuelas de leyes proviene de su particular arraigo político, así como de la especial función que cumplen los abogados. A este cuadro responden igualmente los estándares que deberían cumplirse si se trata de valorar el servicio educativo que brindan las facultades de derecho.

La tesis del mercado no puede pasar por alto esta primera definición y operar sin institucionalidad que delimite los valores en juego. En otras palabras, es necesario que se constituya un sistema de acreditación universitaria como cuestión previa ${ }^{66}$. El carácter constitucional de este sis-

65 Véase el interesante trabajo de REISMAN, Michael. «El diseño del plan de estudios: para que la enseñanza del Derecho continúe siendo efectiva y relevante en el siglo XXI». En La Enseñanza del Derecho... Ob. cit., p. 107.

$66 \mathrm{Al}$ respecto, el Tribunal Constitucional reconoce el carácter público del servicio a la educación, que debe brindarse en condiciones de calidad. Por ello, se hace necesario el establecimiento de mecanismos e instituciones de supervisión: «Por tanto, la supervisión de la calidad de la educación, dependiendo de la oportunidad y del origen de los órganos estatales llamados a ejercerla, debe realizarse ex ante, es decir, antes de que los promotores sean autorizados a desarrollar la actividad educativa; y ex post, a través de una evaluación permanente y rigurosa, que asegure que en ningún intervalo de su ejercicio aquélla se desvincule de la finalidad educativa. [...] Un periódico control externo imparcial llevado a cabo por organismos que no se encuentren vinculados ni directa ni indirectamente con las entidades evaluadas, importaría la implementación de un sistema exigente y 
tema debe su legitimidad a los valores que con él se vertebran, más aún si se piensa en la educación legal. De otro lado, no está demás recordar que ya existen requisitos que deben cumplirse para autorizar el funcionamiento de las entidades universitarias que carecen de un sistema de control sobre su cumplimiento ${ }^{67}$.

Sobre este punto es necesario advertir que los sistemas de acreditación universitaria son compatibles con la actividad de las escuelas de leyes. Incluso los criterios para determinar la solvencia de estos sistemas de acreditación son parte de los propios acuerdos institucionales que deberían llevarse a la práctica y financiarse, legítimamente, a través de distintas fuentes, lo cual dependerá del origen (estatal o privado) de la universidad.

Quizá las universidades privadas creadas al amparo del decreto legislativo 882, que hoy constituyen la mayoría en los órganos rectores de la actividad universitaria, no estén interesadas en impulsar un sistema de acreditación, pues ello sería contrario a sus intereses económicos ${ }^{68}$. En cualquier caso, desde una concepción genuinamente liberal, el Estado está legitimado para crear las condiciones que hagan posible garantizar los bienes públicos implicados por la función que las escuelas de leyes cumplen en el marco de su responsabilidad en una democracia constitucional $^{69}$. Solo la garantía de este escenario puede permitir la existencia de condiciones críticas para la oferta y la demanda del servicio.

La información sobre la realidad en la que se desenvuelve el «mercado» es también necesaria para la existencia de la competencia y para optimizar las condiciones de la elección. Pero no basta que existan reglas que la establezcan y que ella se produzca en apariencia: la información y el cumplimiento de las condiciones necesarias para el desempeño de una

obligatorio de acreditación y auditoria» (fundamento 217 de la sentencia 0017-2008-Al del 5 de junio de 2010).

67 Las consecuencias de este proceso han sido razón para que el Tribunal Constitucional establezca: "Todo lo expuesto permite declarar la existencia de un estado de cosas inconstitucional de carácter estructural en el sistema educativo universitario. Dicho estado solo puede ser reparado en un sentido mínimo con las decisiones adoptadas en esta sentencia, motivo por el cual es obligación del Estado adoptar de inmediato - respetando los criterios expuestos en esta sentencia- las medidas institucionales necesarias (legislativas, administrativas, económicas, etc.) para reformar el sistema de la educación universitaria en el país, de forma tal que quede garantizado el derecho fundamental de acceso a una educación universitaria de calidad, reconocido por la Constitución» (fundamento 217 de la sentencia 0017-2008-Al del 5 de junio de 2010).

$68 \mathrm{En}$ el estado de cosas provocado por la falta control sobre la actividad universitaria, las facultades creadas al amparo del decreto legislativo 882, debido a su presencia mayoritaria en la Asamblea Nacional de Rectores, están en aptitud de tomar las decisiones para optimizar el sistema universitario, pero al parecer hacen lo contrario. El caso de la acreditación se explica en esta línea. Es muy probable que dichas universidades estén más interesadas en no tener tipo de control alguno o, en el peor de los escenarios, un sistema de acreditación hecho a la medida de sus posibilidades o intereses.

69 El sentido liberal de esta afirmación se complementa cuando se afirma que «Una Constitución que no está en grado de garantizar un gobierno eficaz con el respaldo de la opinión pública y no es capaz de aplicar impuestos o de gastar lo que recauda, está destinada, por la fuerza de las cosas, a no proteger los derechos individuales, incluyendo el que implica la capacidad de contratar libremente». La existencia de ciudadanos en pie de igualdad solo es posible si el Estado es capaz de asegurar sus derechos y hacerlos respetar, a través de estructuras públicas, eficaces, honestas y dotadas de autoridad. Véase HOLMES, Stephen y Cass R. SUNSTEIN. The cost of rights. Why liberty depends on taxes. Nueva York: W. W. Norton, 1999, p. 55. 
facultad de Derecho son datos cruciales si se trata de establecer la competencia igualmente crítica en torno a este tipo de servicio ${ }^{70}$.

El contexto no puede dejar de considerar, entonces, la pobreza, la desigualdad y la exclusión, pues, como afirma Sen ${ }^{71}$, ellas son condiciones para el ejercicio de los derechos y las libertades. En la práctica constituyen limitaciones para el acceso a la información que se agrava si la información es escasa. Entonces, será inevitable que los intereses económicos se maximicen sin control legítimo, como resultado de la venta de los servicios y recursos que la demanda requiere. La asimetría o escasa información que impide el ejercicio de derechos y libertades no es algo que pueda corregirse en una democracia constitucional por obra del mercado. El argumento contrario haría suponer que quienes pueden beneficiarse de este hecho — es decir, quienes ofrecen el servicio- se impongan un límite de orden altruista. Una condición básica para que esto no ocurra es la existencia del sistema de acreditación y el control sobre su cumplimiento.

El mercado, desde una óptica crítica, incorpora también las demandas de acceso a la justicia y los derechos de los grupos sociales que se encuentran en una posición de desventaja o exclusión. Este aspecto debería ocupar un lugar específico en el universo de preocupaciones que justifican el plan de estudios y el perfil del abogado. No se entiende, por ello, que se pase por alto y no se establezca una definición en términos curriculares que pueda tener un carácter transversal. $\mathrm{Al}$ margen de la posición ideológica que esté detrás, la función que cumplen las facultades de Derecho justifica plenamente esta consideración.

El mercado, desde este enfoque, define mejor su papel como espacio de agregación de preferencias: un instrumento idóneo para satisfacer y optimizar los valores de la democracia, representados por la función que cumplen las facultades de Derecho. Por ello, lo que puede estar en juego como parte de la competencia, si se piensa en el mercado, es la elección de las condiciones y diseños para realizar los fines de la educación legal, en el marco del sistema de controles razonables o acreditación que le es consustancial.

La información que podría reflejar los distintos enfoques institucionales, y sería útil para contribuir a mejorar la elección del interesado en estudiar derecho, se revela a partir de los siguientes criterios: (i) la plana de profesores y los énfasis que se desprenden de su calificación académica y experiencia profesional para la propia vida institucional; (ii) los diversos acentos o enfoques temáticos que se hacen visibles en los planes

70 Como advierte el profesor Sunstein, la competencia en un sentido relevante tiene un contenido substancial, de ahí que «Si la competencia en los mercados produce discriminación, el problema para las actuales políticas federales no se debe a la ausencia de agresivas leyes antidiscriminatorias sino más bien a la ausencia de una verdadera competencia en el mercado». Véase SUNSTEIN, Cass. Free markets and social justice. Nueva York: Oxford University Express, 1997, p. 151.

71 SEN, Amartya. Desarrollo y libertad. Barcelona: Editorial Planeta, 2000, pp.15-16. 
de estudios; (iii) las especialidades que busquen fortalecer determinadas áreas; (iv) las opciones de inserción en la vida profesional y los espacios laborales previstos que los egresados desempeñan; (v) las oportunidades para internacionalizar los estudios y el ejercicio de la profesión; (vi) las relaciones institucionales nacionales e internacionales de las facultades de Derecho; (vii) los recursos materiales, tecnológicos y bibliográficos.

No se trata de un esquema estático, pues este tipo de decisiones están marcadas por el contexto social y cultural. Así, la idea del ascenso social que está detrás de los estudios universitarios junto a la imagen de poder que se atribuye a la profesión legal, pueden combinarse para influir en la decisión de estudiar derecho, fuera de toda consideración relativa a la calidad del servicio, a las posibilidades de inserción laboral o subempleo, que en el caso de la profesión legal parece constituir un grave problema. En esa dirección, sin control sobre la actividad de las facultades de Derecho, el espacio profesional de los abogados, que no es otro que el de la democracia constitucional, quedaría progresivamente definido por las mismas carencias en contenido y valores de la formación legal.

Por lo dicho, el perfil profesional del abogado debe responder al mercado en forma crítica. Antes que para someterse a una lógica determinista en función de cualquier demanda, el perfil debe aspirar a cumplir una función transformadora de la realidad. El contenido valorativo que implica la enseñanza del Derecho — como se ha dicho- debe calificar al sujeto para que sea capaz de tomar decisiones y enfrentar las carencias de la realidad, así como para avanzar a costa de ella cuando le sea adversa ${ }^{72}$. Para aspirar a cumplir con estas premisas, el perfil del abogado no debe asumirse como una entidad fija en el tiempo y, por ello, no deben fijarse consensos estáticos que impidan ajustar su articulación desde el plan de estudios $^{73}$. El perfil del abogado debe comprometerse con la formación para enfrentar problemas jurídicos con conocimientos y destrezas específicas (especialización), pero con conciencia de su articulación a los valores de la democracia como un todo.

La principal virtud reclamada a un sistema de enseñanza del Derecho radica en la responsabilidad de formar abogados comprometidos con la idea de propiciar — sea cual fuere el tipo de ejercicio profesional- ámbitos de desarrollo social más predecibles, solidarios y justos. Esta aspiración se conecta con el sentido político que redefine el papel de las escuelas de Derecho y se convierte en un derrotero para repensar los planes de estudios, las destrezas, los perfiles profesionales, así como los compromisos de la función docente. 